\title{
PROFESSORES DE CIÊNCIAS EM FORMAÇÃO E A EDUCAÇÃO AMBIENTAL: VIVÊNCIAS E PERSPECTIVAS
}

Yuri Cavaleiro de Macêdo Coelho'

Altem Nascimento Pontes ${ }^{2}$

Resumo: Objetivou-se, neste estudo, investigar as vivências e perspectivas de professores de ciências em formação no ensino básico e universitário, relacionados à Educação Ambiental (EA). Desta forma, coletou-se informações em uma instituição pública de Ensino Superior, através da aplicação de questionário junto a professores de ciências em formação acadêmica de diferentes semestres, totalizando 64 discentes. Os dados possibilitaram identificar que metodologias que minimizam o espaço para a discussão e o diálogo de questões ambientais predominam em possíveis posicionamentos metodológicos dos licenciandos investigados. Nas vivências acadêmicas, constatou-se que a aproximação com a dimensão ambiental ocorre, predominantemente, por meio de elementos fora do currículo tradicional. Assim, conclui-se que o processo de formação de professores como educadores ambientais é deficitário, tanto no ensino básico quanto no superior.

Palavras-chave: Formação de Professores; Temas Transversais; Ensino Superior. 


\section{Introdução}

Após 1977, com a Conferência Intergovernamental sobre Educação Ambiental, realizada em Tbilisi, Georgia (ex-URSS), inicia-se uma mobilização global pautada na criação de uma nova visão sobre valor da natureza no sentido de reorientar a produção do conhecimento baseada, sobretudo, em métodos interdisciplinares que permitem articular as dimensões ambiental e social (JACOBI, 2005; LOUREIRO, 2004). Proposta no Brasil em 1999, a educação ambiental emerge na perspectiva de promover a reflexão dos problemas ambientais de forma dinâmica, coletiva, cooperativa, contínua, interdisciplinar, democrática e participativa, através de uma abordagem crítica e emancipatória, voltados para a construção de sociedades sustentáveis (TOZONI-REIS, 2006)

A Legislação Ambiental (BRASIL, 2008), Lei № 9.795, de 27 de abril de 1999, artigo no 2 e 3, promulga a educação ambiental como um componente essencial e permanente da educação nacional, devendo estar presente, de forma articulada, em todos os níveis e modalidades do processo educativo, em caráter formal e não-formal. Segundo Butzke; Pereira; Noebauer (2007) existem parâmetros que norteiam o processo educativo da educação ambiental em todas as suas variantes, quais sejam: a sensibilização; a percepção da realidade/conhecimento; as ações participativas; o acompanhamento; e a elaboração de bons materiais didáticos.

Neste campo de estudo, considera-se importante que a relação teoria e prática estejam em diálogo permanente, para que através da sensibilização, os sujeitos humanos sejam capazes de manifestar ações de responsabilidade ambiental, isto é, exercitar a práxis (BERNAL, 2015). Embora expostos estes fundamentos e considerações, a educação ambiental ainda enfrenta entraves significativos relacionados, principalmente, aos procedimentos metodológicos para abordagem de tais temáticas (SOUZA, 2014).

Libâneo (2011) defende como aspectos fundamentais para exercício da atividade docente a crítica à teoria aliada à contextualização e uso de metodologias de ação. Sob esta ótica, é importante que às temáticas ambientais sejam trabalhadas nas instituições de ensino em atividades geradoras de discussões que despertem o poder de reflexão e o senso crítico dos estudantes, no intuito de se tornar efetivamente um tipo de educação transformadora de hábitos, conscientizadora (LAYRARGUES, 2001).

Antagônico a esta perspectiva, em seus estudos, Cachapuz et al. (2011, p. 98) critica a forma como as ciências estão sendo ensinadas, uma vez que muitas das metodologias utilizadas pelos professores em sala de aula possuem caráter apenas demonstrativo dos fenômenos explicados de forma teórica, inibindo o processo de elaboração de hipóteses e construção do conhecimento.

Ao realizar uma breve análise da deficiência da grande ineficácia das metodologias na aprendizagem dos estudantes, percebe-se a importância do processo de formação inicial de professores, uma vez que este, na maioria das vezes, está apoiado nos mesmos arcabouços teóricos ultrapassados

Revbea, São Paulo, V. 13, № 2: 121-136, 2018. 
enraizados na essência das universidades que pouco induzem seu público ao entendimento de conceitos através da diversidade metodológica, distanciando teoria da prática (NUNES; SILVA, 2000). Malucelli (2007, p. 114) propõe que, durante o período de formação, futuros professores devem desenvolver habilidades como: apresentar capacidade de crítica fundamentada no ensino habitual; saber preparar atividades; saber avaliar; utilizar a pesquisa e a inovação etc.

Entretanto, é importante ressaltar que as crenças, concepções e práticas dos professores em geral, além de serem influenciadas pelas experiências acadêmicas, somam-se as vivências sociais, individuais e escolares (CURY, 2001). Assim como a formação do aluno que não está centrada, unicamente, nos conhecimentos construídos nas disciplinas, mas por intermédio e influência das relações existentes entre o discente e o espaço escolar/universitário, que contribuem reforçando valores e construindo visões de mundo, conceito de currículo oculto (BIANCHINI; SANTINON; GOMES, 2011).

Diante do exposto, o presente estudo pretendeu investigar as vivências e perspectivas de professores de ciências em formação durante o ensino básico e universitário, relacionados à educação ambiental.

\section{Materiais e Métodos}

Esta pesquisa configurou-se a partir de uma abordagem explicativaqualitativa. Segundo Gil (2008), a pesquisa explicativa objetiva identificar os fatores que determinam ou contribuem para a ocorrência dos fenômenos, sendo um tipo de pesquisa que aprofunda o conhecimento da realidade. De acordo com Silveira; Córdova (2009), na abordagem qualitativa enfatiza-se o aprofundamento da compreensão de um grupo social, logo se atribui relevante importância a observação e registro dos dados

Realizou-se esta pesquisa junto ao curso de Licenciatura em Ciências Naturais - Habilitações Química, Física e Biologia, da Universidade do Estado do Pará (UEPA). A escolha se deu pelo fato de que a UEPA oferta cursos de formação acadêmica de professores a mais de 22 anos, desenvolvendo ações de ensino, pesquisa e extensão nas áreas da Saúde, da Educação e da Tecnologia, segundo o portal virtual da instituição (2016).

Escolheu-se o curso de Licenciatura em Ciências Naturais e suas respectivas habilitações pois os conteúdos que são ministrados nas escolas de educação básica pelos professores graduados nesta disciplina e afins estão fortemente relacionados à discussão de temáticas ambientais, de acordo com o Projeto Político Pedagógico (PPP) do curso (UEPA, 2009). Sobre este ponto de vista, torna-se eficaz e próximo da realidade escolar a investigação científica que este estudo se propõe a fazer.

O público-alvo desta investigação científica foram os discentes do curso de Licenciatura Plena em Ciências Naturais, das habilitações Biologia, Física e Química, uma vez que ao integrar um curso de formação de professores é 
possível obter informações referentes a educação ambiental no processo de formação pré-profissional e acadêmica, logo o tipo de amostragem utilizada é do tipo não probabilística por julgamento (SCHIFFMAN; KANUK, 2000; ARIBOMI; PERITO, 2004).

O estudo apresenta heterogeneidade nos tamanhos das amostras, devido às diferentes quantidades de graduandos por turma. Participaram da pesquisa 3 turmas, um total de 64 alunos regularmente matriculados em uma das habilitações no curso citado. Os discentes foram consultados na qualidade de professores em formação para reflexão da prática docente, pela qual foram formados no ensino básico, e das experiências na universidade.

Para coleta de dados, solicitou-se aos estudantes que respondessem a um questionário com perguntas abertas e fechadas, haja vista que este instrumento serve para coletar informações da realidade buscando compilar pontos de vista, crenças, vivências, expectativas e interesses (GIL, 2008). Assim, aplicou-se este método para que fossem obtidas informações acerca do processo de formação, interesse, conhecimento e desenvolvimento prático de atividades voltadas à educação ambiental na vivência escolar básica e universitária.

Antes de cada aplicação de questionário foram expostas a natureza e intuito da pesquisa através de conversas informais, sendo solicitada aprovação dos entrevistados para registrar as informações e assinatura do Termo de Consentimento Livre e Esclarecido.

Utilizou-se a análise de conteúdo para proceder a análise dos dados coletados, devido esta técnica permitir a inferência de conhecimentos que dizem respeito ao processo de produção e/ou recepção das comunicações de forma quantitativa e qualitativa (BARDIN, 2011). Para tal, realizou-se a préanálise dos dados; seguida da exploração do material; e, por fim, o tratamento dos resultados, a inferência e a interpretação, seguindo as etapas definidas por Bardin (2011).

Para fim de levantar as disciplinas do curso que realizam a abordagem da educação ambiental e meio ambiente, realizou-se análise documental do PPP do curso investigado. Examinou-se todas as disciplinas ofertadas pelo curso nas suas habilitações, nos seguintes aspectos: ementa, conteúdo programático e bibliografias sugeridas.

Desta forma, apresentar-se-ão os resultados e as análises destes no tópico seguinte, sendo que para cada pergunta do tipo aberta do questionário foram elaboradas categorias que sintetizam respostas afins. 


\section{Resultados e Discussão}

A pesquisa contou com a participação de 64 professores em formação, sendo: 26 do terceiro semestre de Ciências Naturais com habilitação em Biologia, 15 do quinto semestre com habilitação em Física e 23 alunos sétimo período de habilitação em Química. Deste quantitativo, 37 eram do sexo feminino e 27 do sexo masculino, com faixa etária entre 18 e 25 anos.

Para análise das vivências escolares pré-profissionais, os graduandos foram perguntados quanto à frequência de abordagem das questões relacionadas ao meio ambiente durante a educação básica.

Identificou-se que a grande maioria dos alunos de todas as turmas consultadas tiveram contato poucas vezes com as temáticas ambientais durante o Ensino Fundamental (Figura 1.a) e o Médio (Figura 1.b), 61\% e 70\% do total dos estudantes que responderam o questionário, respectivamente. De acordo com estes dados, entende-se que a dimensão ambiental é comumente articulada nas escolas em ações simples, pontuais e descontínuas (BIZERRIL; FARIA, 2001).

Contudo, observa-se nos gráficos que existe uma parcela significativa de escolas que se dedicam a explorar as temáticas ambientais em suas vertentes. Nos estudos de Trajber; Mendonça (2006) tal fato também pôde ser percebido, pois estes autores notaram um crescimento na abordagem da educação ambiental, apontando fatores que justificam este processo, como: as novas possibilidades metodológicas, a diversificação na formação profissional e a globalização.

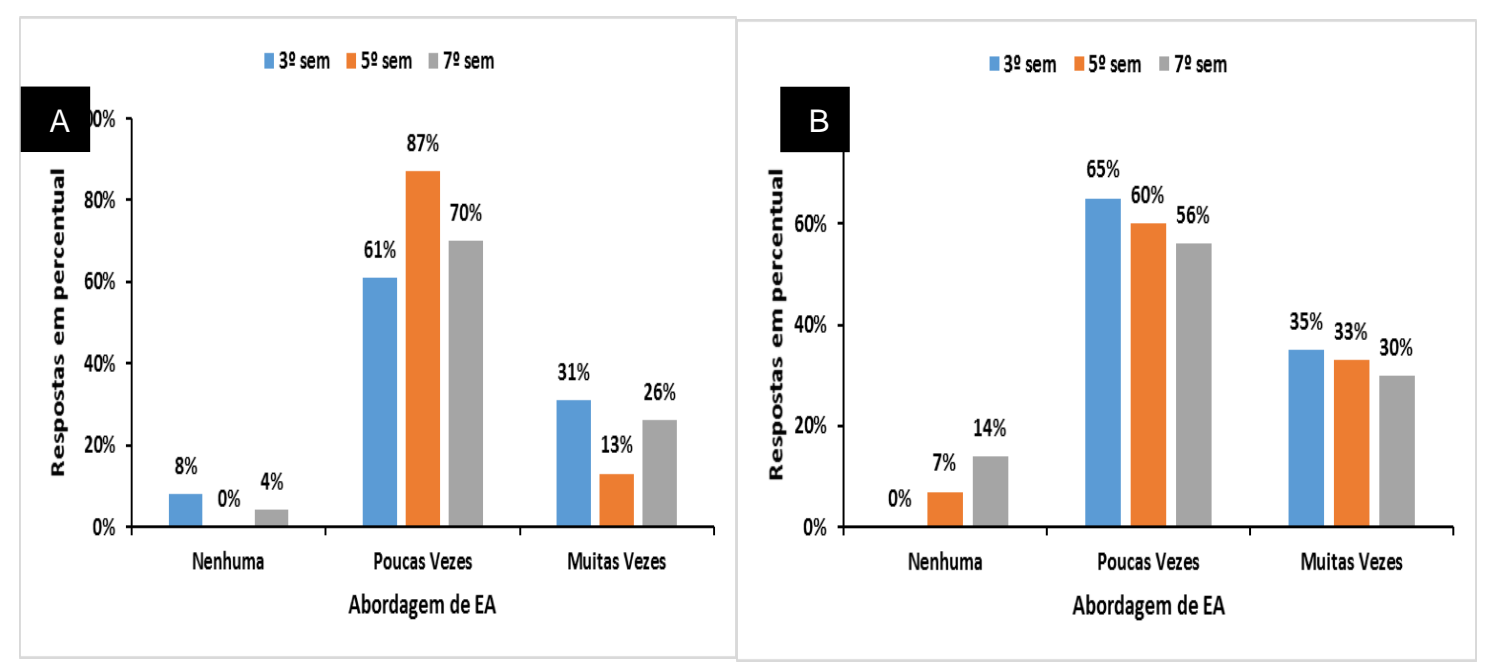

Figura 1: A - Gráfico de Frequência da Abordagem de EA no Ensino Fundamental; B - Gráfico de Frequência da Abordagem de EA no Ensino Médio.

Fonte: os autores.

Embora com pouca expressividade, notou-se que, mesmo com as crescentes discussões sobre o meio ambiente, ainda existem escolas que não 
proporcionam debates sobre estes temas a seus alunos, como o expresso na Figura 1, gráficos A e B. Estes dados revelam, além de uma deficiência relevante quanto ao planejamento educacional, a falta de compromisso das escolas com uma necessidade básica exposta pelos Parâmetros Curriculares Nacionais (PCN), que é tratar as problemáticas que interferem na vida dos alunos e com as quais são expostos diariamente, de acordo com as demandas da sociedade atual (BRASIL, 1997).

No intuito de verificar a prática escolar dos PCN, no que diz respeito à abordagem do Meio Ambiente como tema transversal, nas vivências de futuros professores durante o ensino básico, perguntou-se quais disciplinas se valiam de metodologias para promover EA. Nesta pergunta os alunos poderiam assinalar mais de uma disciplina, com isso obteve-se um total de 170 respostas, a frequência destas por disciplina estão expostos na Figura 2.

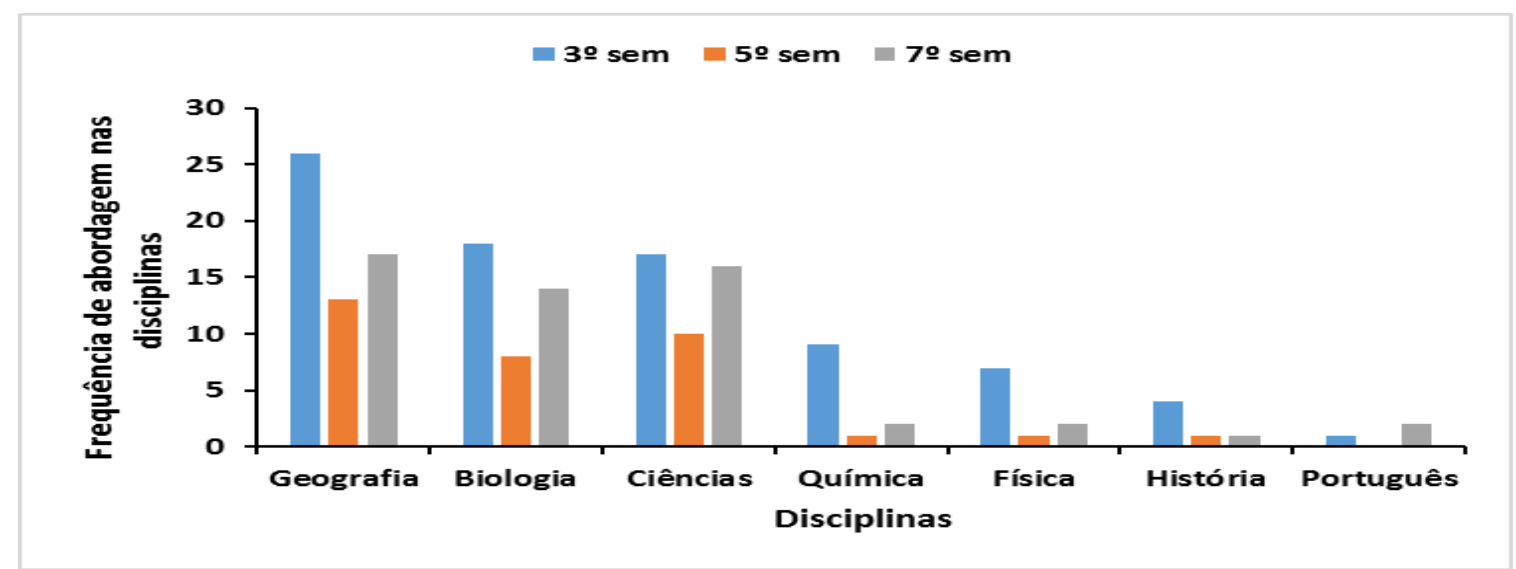

Figura 2: Gráfico - Abordagem de EA por disciplina da Educação Básica Fonte: os autores.

Verifica-se que a grande maioria dos alunos, de todas as três turmas questionadas, afirmam que a abordagem ocorreu através das disciplinas Geografia, Ciências Naturais e Biologia, sendo citadas 56, 43 e 40 vezes, respectivamente. Outros estudos nacionais e internacionais (SATO, 1997; ROBOTTON, 1998; OLIVEIRA, 2007), reafirmam tais resultados ao ressaltar que os temas ligados às questões ambientais parecem estar intimamente atrelados, no processo educacional, às disciplinas de Ciências e Geografia. Com menor frequência, foram citadas as disciplinas: Química (12), Física (10), História (6) e Português (3). O componente curricular Matemática não foi citado.

Com base nos dados, é possível identificar que o princípio da integração curricular através da transversalidade, proposto pelos PCN (BRASIL, 1997) para tratar o meio ambiente, foi adotado de forma deficitária na formação préprofissional da população investigada. Realidade que contrapõe, também, a ideia de que a EA seja tratada de forma interdisciplinar, no intuito de construir conhecimentos globalizantes que transponham a fragmentação disciplinar (FONSECA, 2016).

Revbea, São Paulo, V. 13, № 2: 121-136, 2018. 
Os dados apresentados neste trabalho apontam que a abordagem das temáticas ambientais ainda está fortemente relacionada a disciplinas afins, como: ciências, biologia e geografia, convergindo com os resultados obtidos por Santos; Santos (2015). Vincula-se a alta frequência na disciplina de Geografia as ideias de Monteiro (2016), quando cita que este componente curricular sempre busca instigar o aluno a observar, analisar e compreender a relação entre às transformações do espaço geográfico e a sociedade.

A baixa menção de disciplinas pouco afins a área ambiental muitas vezes é justificada pelo pouco interesse dos professores, necessidade de formação adequada e falta de incentivo das escolas na aproximação entre áreas do conhecimento (OLIVEIRA, 2007). Lemos; David (2011) indicam que os componentes curriculares que se distanciam do debate ambiental, devem servir de apoio no processo de construção de conhecimentos para as disciplinas mais relacionadas, por isso sugerem que sejam desenvolvidas parcerias para se trabalhar o Meio Ambiente.

Os graduandos do curso de Licenciatura em Ciências Naturais e suas Habilitações foram consultados quanto às vivências e perspectivas no ensino superior em relação à EA e Meio Ambiente. Aproximadamente, $78 \%$ dos estudantes admitiram algum tipo de vivência ou contato com informações de qualquer meio relativo às temáticas ambientais durante a vida acadêmica, já outros $22 \%$ afirmaram que não tiveram nenhum tipo de contato. Os indivíduos que manifestaram algum tipo de envolvimento com questões ambientais na universidade alegaram que isto aconteceu por meio de várias fontes, como as apresentadas no gráfico da Figura 3.

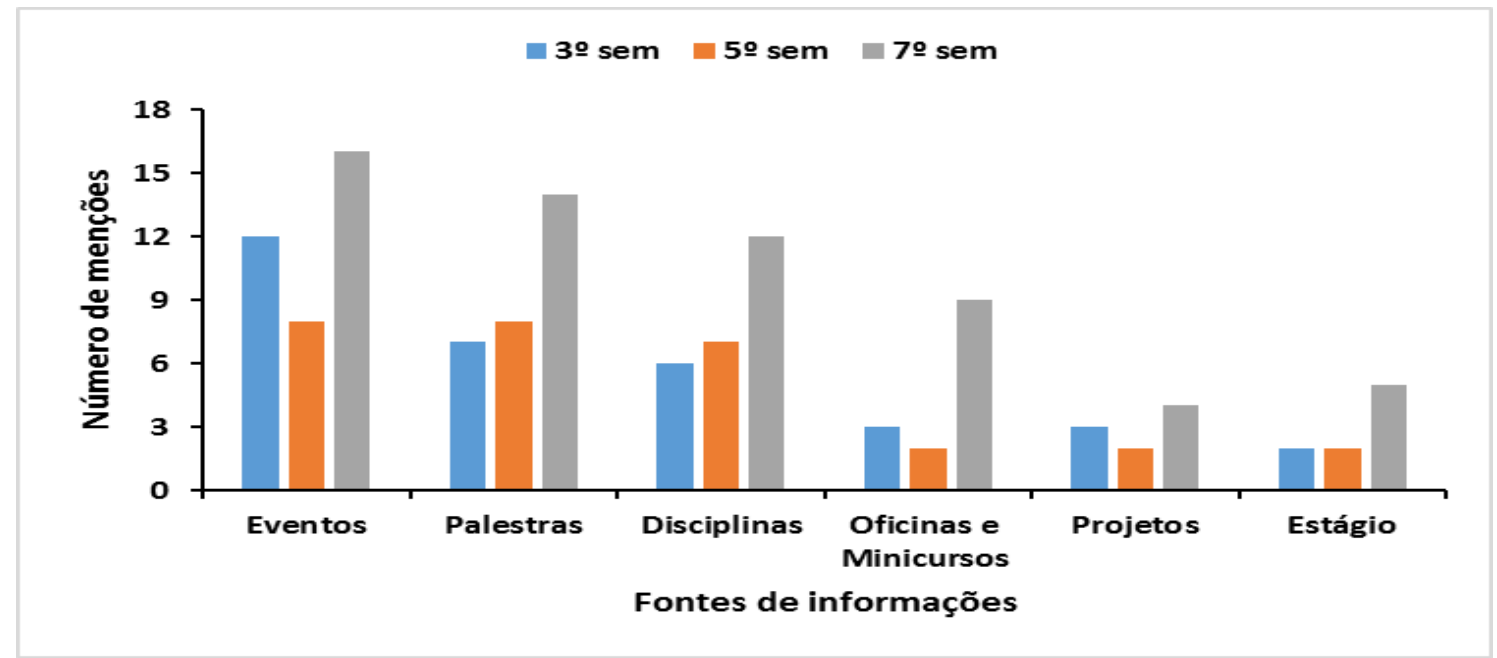

Figura 3: Gráfico - Vivências em EA no Ensino Superior

Fonte: os autores.

Destacam-se como principais formas de obtenção de conhecimentos sobre a temática: os eventos, as palestras e as disciplinas, total de 36, 29 e 25 citações, respectivamente. Em menor frequência, foram mencionadas 
atividades como oficinas e minicurso (14), projetos de extensão (9) e os estágios (9) curriculares e, principalmente, extracurriculares.

A participação de eventos científicos, ao se sobressair em relação as demais fontes, evidencia estes como um importante mecanismo de construção de conhecimentos que auxilia para um processo formativo consolidado, contribuindo para atuações profissionais mais seguras, na medida em que estimula o desenvolvimento de habilidade e competências (SILVA, 2013). Na pesquisa de Tavares et al. (2007), identificou-se que as atividades extracurriculares e experiências durante o período de formação podem influenciar nas posturas de profissionais em seus campos de trabalho, no futuro.

Através dos resultados, infere-se que estes futuros professores de ciências reconhecem que a formação acadêmica transpõe o estabelecido pelo currículo formal, ao buscar em outras atividades, fontes de conhecimentos e vivências, como expresso nas respostas dos estudantes:

"Participei de palestras e um simpósio sobre temas ambientais relacionados à Amazônia" (Maria ${ }^{3}$, aluna $7^{0}$ semestre).

"Até agora, no curso em si, houve pouca abordagem sobre Educação Ambiental, mas acompanhei o assunto em cursos complementares" (Rita, aluna $3^{\circ}$ semestre).

Sob uma a ótica da proporcionalidade entre os dados, observou-se que há relação significativa entre a frequência de menção das fontes de conhecimento e o avançar dos semestres, ou seja, alunos com estudos mais avançados tiveram contato maior com os temas ambientais, em todas as fontes citadas. Possivelmente, isso se deve ao fato de que os alunos do quarto ano já passaram por grande parte das disciplinas e tiveram mais tempo para realizar atividades complementares, quando comparados aos alunos do segundo ano, por exemplo.

Em relação à grande menção das disciplinas como fontes de informação das temáticas ambientais, permite-se justificar esta postura tendo como base uma breve análise do PPP do curso de Licenciatura em Ciências Naturais e suas Habilitações. Identificou-se neste documento que é previsto no currículo formal, principalmente em disciplinas pedagógicas, a abordagem da dimensão ambiental nas ementas, nos conteúdos estabelecidos e nas bibliografias sugeridas para as disciplinas.

Através do PPP do curso (UEPA, 2009), notou-se que os seguintes componentes curriculares favorecem à discussão da EA: Tendências Educacionais para o Ensino de Ciências, primeiro semestre, discute a EA com

${ }^{3}$ Utilizou-se nomes fictícios na descrição das respostas para preservar a identidade dos sujeitos.

Revbea, São Paulo, V. 13, № 2: 121-136, 2018. 
seus princípios e fundamentos; Práticas Integradoras I e II, terceiro e quarto semestre, respectivamente, visam integrar a dimensão teórica e prática de atividades interdisciplinares das ciências com base em suas tendências, podendo realizar a abordagem de temas transversais como Meio Ambiente e Sociedade; Temas de Biologia I, segundo semestre, disciplina na qual é ministrado conteúdos como Ecologia e Meio Ambiente, tendo bibliografia específica para tal; e Políticas Educacionais, através desta os estudantes possuem a oportunidade de estudar e debater os PCN.

Não obstante, os alunos foram unânimes em considerar que é bastante relevante a discussão de temáticas relacionadas ao Meio Ambiente durante o período acadêmico, pois, como futuros professores, necessitam desenvolver a habilidade de saber abordar e debater sobre a dimensão ambiental com seus alunos. Constata-se, através dos dados, que os licenciandos apresentam noção da importância das ciências ambientais na universidade, pois esclarece as dúvidas, atribui uma base teórica e os ensina a desenvolver conversas com os futuros alunos sobre o tema, cientes que o espaço escolar é a principal, por vezes única, fonte de informações sobre estes assuntos, como exposto nas respostas a seguir:

"Nós, futuros professores, necessitamos falar do meio ambiente e tornar a educação ambiental uma rotina escolar, para que possamos conscientizar nossos alunos, então é muito importante ter o contato com esses assuntos desde a universidade" (Caio, graduando do $3^{\circ}$ semestre).

"A abordagem é importante porque desconstrói pensamentos e atitudes sobre estes temas [ambientais] e mostra o verdadeiro conceito e aplicações destes" (Luana, graduanda 5ํㅗㄴ semestre).

Visualiza-se nos relatos que os licenciandos pesquisados manifestaram, de diversas formas, interesse em conhecer mais sobre a temática, para saber como orientar os seus alunos no futuro a respeito destes assuntos. Além disso, demonstraram alguns pontos positivos que a ampliação das discussões sobre estes temas pode atribuir para o desenvolvimento tanto pessoal quanto profissional, tal qual evidenciado neste escrito:

"Minha maior expectativa é poder desenvolver habilidades, durante o ensino superior, que me permitam relacionar os problemas ambientais com a realidade dos alunos, representar logicamente as diversidades e dificuldades, e poder esclarecer de forma clara os assuntos que despertam esta temática" (lago, cursando $5^{\circ}$ semestre). 
Estes dados e relatos demonstram a importância do processo de formação dos professores nas ações profissionais futuras, confirmando o observado na pesquisa desenvolvida por Chaves e Farias (2005) quando apresentam que a principal dificuldade de professores atuantes para a realização de projetos em EA é ocasionada pela falta de formação adequada.

Os licenciandos foram questionados sobre as perspectivas individuais de contato com EA que o período na academia pudesse lhes oportunizar. Os licenciandos puderam escrever quantos tipos de abordagem desejassem. Agruparam-se, então, as respostas desta pergunta em três categorias, de acordo com a forma de abordagem pretendida, são elas: Atividades nas disciplinas; Atividades extracurriculares; e a Elaboração de Projeto de EA (Figura 4).

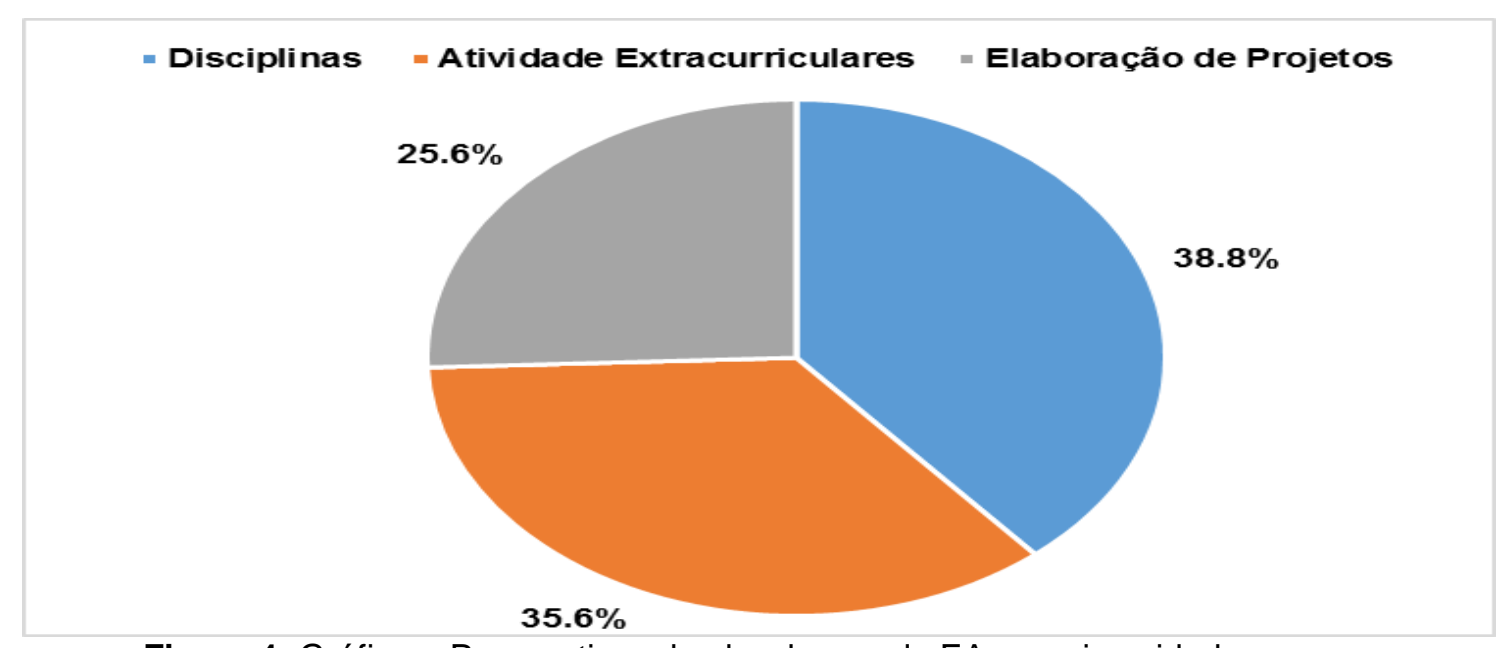

Figura 4: Gráfico - Perspectivas de abordagem da EA na universidade

Fonte: os autores.

Identificou-se que a maioria dos alunos depositam suas expectativas relacionadas à discussão das questões ambientais nas disciplinas que compõem a matriz curricular tradicional do curso $(38,8 \%$ do total de respostas dos estudantes), ao citar que desejam: elaborar recursos didáticos que promovam EA, realizar visitas técnicas e participar de discussões e debates em sala sobre Meio Ambiente. Uma parcela bastante significativa, alegou que aspiram formação através da participação de atividades extracurriculares (35,6\% das respostas), foram citadas: participação em eventos, oficinas e/ou minicursos. Parte dos alunos demonstraram pretensão em desenvolver projetos que envolvem EA ( $25,6 \%$ das respostas).

Com base no exposto, infere-se que os alunos de graduação possuem perspectiva por atividades, disciplinares ou não, que tratem a EA e o Meio Ambiente. Por esta real necessidade os PCN (1997) sugerem que os temas ambientais sejam trabalhados no Ensino Superior em diversos cursos e, principalmente, no processo de formação inicial de professores, item reproduzido pela Lei 9.795/99, artigo 11, da legislação ambiental, quando 
promulga que "[...] a dimensão ambiental deve constar dos currículos de formação de professores, em todos os níveis e em todas as disciplinas".

Contudo, muitas vezes, as perspectivas e as próprias políticas para desenvolvimento da EA no Ensino Superior na são atendidas por parte das universidades, pois limitam a abordagem destes assuntos em leituras conservadoras e ações pontuais (THOMAZ, 2006). Assim, ressalta-se a importância dos eventos científicos e da elaboração e participação de projeto, pois além de proporcionarem contato com a temática de diversas formas, promovem a interação destes estudantes com a atmosfera interdisciplinar que percorre o tema.

Por fim, traçou-se um comparativo entre a abordagem didáticometodológica das temáticas ambientais dos alunos pesquisados vivenciadas no ensino básico e as possíveis propostas didático-metodológicas que eles utilizariam, na qualidade de professor de Ciências, para trabalhar EA com seus alunos. Todos os graduandos citaram mais de uma metodologia tanto para as que foram utilizadas pelos seus professores no período pré-profissional, quanto as que desejariam utilizar quando professores atuantes

Categorizou-se as respostas obtidas de acordo com o estabelecido por Tozoni-Reis (2007) ao apontar cinco formas de abordagem metodológica para EA (Figura 5), quais sejam: a disciplinatória, promotora de mudanças de comportamentos ambientais; a emancipatória, pretende conceber a EA como um processo de apropriação crítica e reflexiva de conhecimentos, atitudes, valores e comportamentos; a lúdica, promotora de sensibilização ambiental; a pesquisa-ação-participativa, visa intervir para promover a redução dos efeitos predatórios das ações antrópica na natureza; e a técnica, possui caráter informacional, transmissão de conhecimentos científicos a respeito dos processos ambientais.

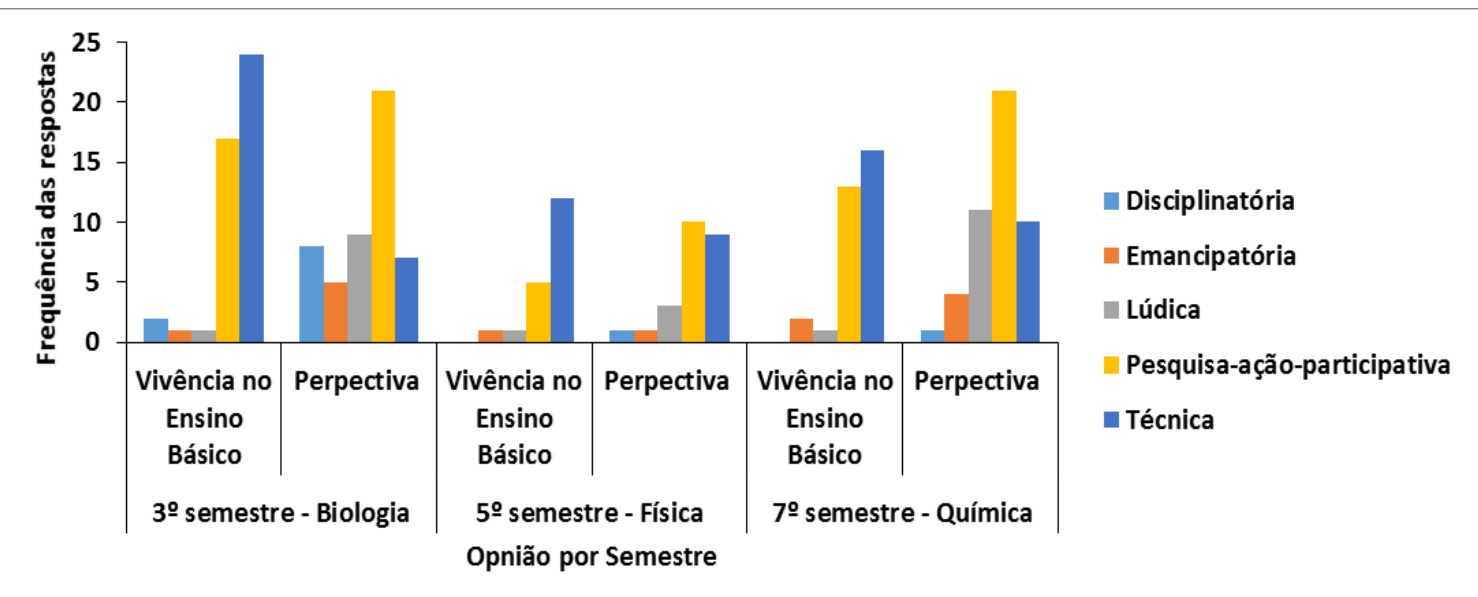

Figura 5: Gráfico - Formação individual e perspectivas profissionais de abordagem da EA Fonte: os autores. 
Através das respostas, observa-se que os licenciandos pouco pretendem utilizar o método mais presente durante os seus processos de formação básica, a metodologia técnica, materializada nas respostas como: aulas expositivas, seminários e palestras, uma vez que em todos os estratos pesquisados ocorre significativa diminuição entre vivências e perspectivas nesta categoria. Wollman; Soares; Ilha (2015) constatam que a maioria dos professores que tratam o meio ambiente em suas aulas, independente da área do conhecimento, utilizam metodologias informacionais.

Aponta-se que a metodologia do tipo pesquisa-ação-participativa é a que os graduandos mais pretendem utilizar em seus postos de trabalho futuramente, ao expressarem que utilizariam atividades práticas como: construir terrários, plantar mudas e praticar reutilização de materiais. Porém, visualiza-se que esta estratégia metodológica foi pouco durante a formação básica da população pesquisada. A partir disto, presume-se que o alto índice nesta abordagem metodológica possa ser influenciado pelas experiências que mais atraíram a atenção dos licenciandos em seus processos de formação básica e universitária.

Conforme apresentado por Berbel (2011), metodologias ativas de ensino despertam a curiosidade dos alunos, e interesse pela apresentação teórica do assunto, à medida que estes se inserem na exposição do conteúdo, acrescentando novos elementos, por vezes não analisados pelo próprio educador, o que pode estimular a sensibilização individual com reflexos sociais. Dessa forma, torna-se possível que o aluno adquira autonomia e ânimo para explorar determinados assuntos.

Contraditoriamente, identificou-se nas vivências e perspectivas relatadas baixa expressividade no uso de metodologias emancipatórias, quais sejam: discussões, debates, desenvolvimentos de projetos e campanhas etc. Refletindo, deste modo, Leff (2012, p. 243) expressa que "a educação interdisciplinar entendida como a formação de mentalidades e habilidades para apreender a realidade complexa, reduziu-se à incorporação de uma 'consciência ecológica' no currículo tradicional'.

Nota-se, que, embora o pouco contato com as estratégias de abordagem lúdica para EA durante o ensino básico, os graduandos a implementariam em sua prática docente. É sabido que este tipo de prática pedagógica para tratar de $E A$, ou qualquer outro assunto, só se torna válida quando a mediação do professor oportuniza aos estudantes refletir, investigar e contextualizar ideias de forma mais divertida, no intuito de elaborar hipóteses e visualizar as situações no cotidiano (MARIA et al., 2009).

\section{Considerações Finais}

A partir das análises apresentadas nessa pesquisa sobre a formação pré-profissional e inicial de professores como educadores ambientais, ressaltase a importância do período acadêmico na construção de profissionais da educação, no que diz respeito ao aprofundamento de conhecimentos teórico e 
prático para abordagem do meio ambiente com seus futuros alunos. Indica-se que possíveis ações laborais de professores possam ser influenciadas pelas vivências que os formaram também durante a educação básica. Ademais, pondera-se que o meio acadêmico possa oportunizar, de várias formas, reflexões sobre meio ambiente que transpõem o estabelecido pelo currículo disciplinar tradicional estabelecido nos PPP.

No entanto, é fato que a formação para abordagem de temáticas ambientais ainda se alicerça no repasse de informações técnicas que pouco exploram as interfaces crítica, subjetiva e humana. Possivelmente, esta linha de instrução poderá, também, refletir na prática docente destes futuros professores, o que já se pôde observar nas respostas dos licenciandos quando questionados sobre possíveis propostas didático-metodológicas que seriam utilizadas eventualmente em práticas profissionais futuras.

Assim, infere-se que as experiências pessoais, intrínsecas a individualidade humana, e o posicionamento profissional são interdependentes, ou seja, é impossível separar estas duas dimensões. Deste modo, é válido salientar a importância da discussão da dimensão ambiental durante toda a vida do indivíduo e, principalmente, em cursos de formação de professores, no intuito de desenvolver habilidades e competências nestes futuros profissionais para que possam formar cidadãos conscientes e conhecedores da realidade social a qual estão inseridos.

Apesar deste estudo estabelecer enfoque no processo de formação de professores de Ciências, destaca-se a defasagem da concepção de que trabalhar EA compete apenas a professores formados nas áreas das Ciências, Biologia e Geografia, como expresso nos dados, uma vez que esta visão pouco contempla a formação universal e crítica dos estudantes. Como estabelecido pelos PCNs (1997), o meio ambiente dever ser abordado de forma transversal a fim de atender as realidades do universo escolar.

\section{Agradecimentos}

Aos discentes do Curso de Licenciatura em Ciências Naturais - Habilitações Biologia, Química e Física por terem confiado e permitido a realização desta pesquisa. À Coordenação de Aperfeiçoamento de Pessoal de Nível Superior (CAPES), pelo apoio financeiro à pesquisa. Ao Programa de Pós-graduação em Ciências Ambientais (PPGCA-UEPA), pelo estímulo a prática científica e formação acadêmica a nível de mestrado do primeiro autor.

\section{Referências}

ARIBONI, S; PERITO, R. Guia Prático para um projeto de pesquisa exploratória, experimental, descritiva. 1 ed. São Paulo: Unimarco, 2004.

BARDIN, L. Análise de Conteúdo. 6 ed. Tradução Luis Antero Reto, Augusto, Pinheiro, São Paulo: Edições 70. 2011. 
BERBEL, N.A.N. As metodologias ativas e a promoção da autonomia de estudantes. Semina : Ciências Sociais e Humanas, Londrina, v. 32, n. 1, p. 2540, jan./jun. 2011.

BERNAL, A.B. (Org.). Apoio à implementação do Programa de educação ambiental e agricultura familiar nos territórios: volume 4 - Fundamentos e estratégias para a educação ambiental na agricultura familiar. Brasília: MMA, 2015.

BIANCHINI, D., SANTINON, I.T.G., GOMES, F.S.C. (2011). O Currículo Oculto e seus Mitos na Educação em Engenharia. In CONGRESSO BRASILEIRO DE EDUCAÇÃO EM ENGENHARIA, 39., 2011, Blumenau. Anais... Blumenau: COBENGE, $2011 . \quad$ Disponível em: <http://www.abenge.org.br/CobengeAnteriores/2011/sessoestec/art2082.pdf> Acesso: 01 mai. 2017

BRASIL, Secretaria de Educação Fundamental. Parâmetros curriculares nacionais. Secretaria de Educação Fundamental. - Brasília: MEC / SEF, 1997.

BRASIL. Ministério do Meio Ambiente. Consultoria Jurídica. Legislação Ambiental Básica / Ministério do Meio Ambiente. Consultoria Jurídica. Brasília: Ministério do Meio Ambiente, UNESCO, 2008.

BUTZKE, I.C; PEREIRA, G.R.; NOEBAUER, D. Sugestão de indicadores para avaliação do desempenho das atividades educativas do sistema de gestão ambiental - SGA da Universidade Regional de Blumenau, FURB. In: ENCONTRO PESQUISA EM EDUCAÇÃO AMBIENTAL, 1., 2007, Rio Claro. Anais... Rio Claro: USP, 2001. Disponível em: <http://www.epea.tmp.br/epea2001 anais/pdfs/plenary/tr12.pdf> Acesso: 04 mai. 2017

CHAVES, A.L.; FARIAS, M.E. Meio ambiente, Escola e a formação dos professores. Ciência e educação, Bauru, v. 11, n. 1, p. 63-71, 2005.

Disponível em: <http://www.scielo.br/scielo.php?script=sci arttext\&pid=S151673132005000100006\&lng=en\&nrm=iso >. Acesso: 03 mai. 2017.

CURY, H. N. (Org.). Formação de Professores de Matemática: uma visão multifacetada. Porto Alegre: Edipucrs, 2001.

FONSECA, S.M. A Educação Ambiental como Disciplina. Revista Brasileira de Educação Ambiental, São Paulo, v. 11, n. 1, p. 305-314, 2016.

GIL, A.C. Métodos e técnicas de pesquisa social. 6. ed. São Paulo: Atlas, 2008.

JACOBI, P.R. Educação ambiental: o desafio da construção de um pensamento crítico, complexo e reflexivo. Educação e Pesquisa, São Paulo, v. 31, n. 2, p. 233-250, 2005.

LAYRARGUES, P.P. A resolução de problemas ambientais locais deve ser um tema gerador ou a atividade-fim da educação ambiental? In: REIGOTA, M. (Org.). Verde cotidiano: o meio ambiente em discussão. Rio de Janeiro: DP\&A, 2001. p. 1-10.

Revbea, São Paulo, V. 13, № 2: 121-136, 2018. 
LEFF, E. Saber Ambiental: sustentabilidade, racionalidade, complexidade, poder. Tradução de Lúcia Mathilde Endlich Orth. 9. ed. - Petrópolis, RJ: Vozes, 2012.

LEMOS, E.M.; DAVID, C.M. Reflexões sobre o Tema Transversal Meio Ambiente no Ensino Fundamental. CAMINE: Caminhos da Educação, Franca, v.3, n.1, 2011. Disponível em: <https://ojs.franca.unesp.br/index.php/caminhos/ article/view/312>. Acesso em: 27 abr. 2017.

LIBÂNEO, J.C. Didática e trabalho docente: a mediação didática do professor nas aulas. In: LIBÂNEO, J.C.; SUANNO, M.V.R.; LIMONTA, S.V. (Orgs.). Concepções e práticas de ensino num mundo em mudança: diferentes olhares para a didática. Goiânia: CEPED/Editora PUC Goiás, 2011. p. 85-100

LOUREIRO, C. Trajetória e fundamentos da educação ambiental. 2 ed. São Paulo: Cortez, 2004.

MARIA, V.M., ALMEIDA, S., SILVA, A.X., ALMEIDA, B.C., FURTADO, J.L., BARBOSA, R.V.C. A Ludicidade no Processo Ensino-Aprendizagem. Corpus et Scientia, v.5, n. 2, p. 5-17, 2009.

MONTEIRO, G.L. Educação Ambiental no Ensino de Geografia: Uma Contribuição do PIBID para Alunos do Ensino Fundamental. Revista Brasileira de Educação Ambiental, São Paulo, v. 10, n. 1, p. 281-290, 2015.

MONTEIRO, G.L. Educação ambiental no ensino de geografia: uma contribuição do PIBID para alunos do ensino fundamental. Revista Brasileira de Educação Ambiental, São Paulo, v. 10, n. 1, p. 281-290, 2015.

NUNES, C.A., SILVA, E. A Educação sexual da criança. 1 ed. Campinas: Autores Associados, 2000.

OLIVEIRA, T.A. Educação Ambiental e cidadania: a transversalidade da questão. Revista Iberoamericana de Educación, v. 42, n. 42, p. 1-9, 2007. Disponível em: http://rieoei.org/1633.htm Acesso: 05 mai. 2017

ROBOTTOM, I. The role of science in environmental education. In: COSTA, W.C.S.O. (org.) Comunicação da ciência e educação ambiental: resultados do workshop internacional. Belém: Museu Paraense Emílio Goeldi, 1998, p. 45- 50.

SANTOS, A.G.; SANTOS, C.A.P. A Inserção da Educação Ambiental no Currículo Escolar. Revista Monografias Ambientais, Santa Maria, v. 15, n.1, p. 369-380, 2016.

SATO, M. Educação para o ambiente amazônico. 1997. 246 f. Tese (Doutorado em Ecologia e Recursos Naturais) - Centro de Ciências Biológicas e da Saúde, Universidade Federal de São Carlos, São Carlos, 1997. Disponível em: <http://www.lapa.ufscar.br/pdf/tese doutorado michele sato.pdf> Acesso: 05 mai. 2017.

SCHIFFMAN, L.G.; KANUK, L.L. Comportamento do Consumidor. 9 ed. Santana de Parnaíba: LTC Editora. 2000. 
SILVA, H.O.P. Os encontros científicos estudantis: vantagens e principais problema. Múltiplos Olhares em Ciência da Informação, v. 3, n. 2, p. 1-4, 2013.

SILVEIRA, D.T.; CÓRDOVA, F.P. A Pesquisa Científica. In: GERHARDT, T.E.; SILVEIRA, D.T. (Orgs.). Métodos de Pesquisa. Porto Alegre: Editora da UFRGS, 2009. p. 31-42

SOUZA, M.C.C. Educação Ambiental e as Trilhas: Contexto para a Sensibilização Ambiental. Revista de Brasileira de Educação Ambiental, v.9, n.2, p.239-253, 2014. Disponível em: http://www.sbecotur.org.br/revbea/index.php/revbea/article/viewFile/2644/2919 Acesso: 28 abr. 2017

TAVARES, C.H.F.; MAIA, J.A.; MUNIZ, C.H.; MALTA, M.V.; MAGALHÃES, B. R.C.; THOMAZ, A.C.P. O currículo paralelo dos estudantes da terceira série do curso médico da Universidade Federal de Alagoas. Revista Brasileira de Educação Médica, Rio de Janeiro, v. 31, n. 3, p. 245-253, 2007.

THOMAZ, C.E. Educação Ambiental na formação inicial de professores. 2006. 108 f. Dissertação (Mestrado em Educação) - Centro de Ciências Sociais Aplicadas, Pontifícia Universidade Católica, Campinas, 2006. Disponível em: <http://www.bibliotecadigital.puc-campinas.edu.br/tde arquivos/3/TDE-2006-1129T141821Z-1224/Publico/Clelio\%20Estevao.pdf> Acesso em: 02 mai. 2017.

TRAJBER, R.; MENDONÇA, P.R. (Orgs). Educação na diversidade: o que fazem as escolas que dizem que fazem educação ambiental. Brasília: Secretaria de Educação Continuada, Alfabetização e Diversidade, 2006.

UEPA, Departamento de Ciências Naturais. Projeto Político Pedagógico do Curso de Licenciatura Plena em Ciências Naturais e suas Habilitações. Belém, PA: Universidade do Estado do Pará, 2009. 